\title{
建构现代学生学习者身份初探
}

杨晓九日

济南市市中区爱都小学

DOI:10.32629/er.v2i12.2289

[摘 要] 随着互联网的不断普及和社会经济的高速发展, 为了紧跟社会发展的步伐,公众 “终身学习” 的意识也越来越强。在当代发展的背景 下, 学校教育的培养目标也逐渐从传统的知识传授向注重培养学生的批判能力和创造能力过渡。很显然, 传统学校的教学空间已经慢慢脱节社会 发展的需要和教育教学的变革。在现代学习空间中,学习是一种与学生个体的内在相关联的、更加多元化的和极具赋有意义的活动,其所赋予个 体的符号不再是学生而是学习者。

[关键词] 建构; 现代; 学习者

随着互联网的不断普及和社会经济的高速发展, 为了紧跟社会发展的 步伐, 公众 “终身学习” 的意识也越来越强。在当代发展的背景下, 学校教 育的培养目标也逐渐从传统的知识传授向注重培养学生的批判能力和创 造能力过渡。很显然, 传统学校的教学空间已经慢慢脱节社会发展的需要 和教育教学的变革。在现代学习空间中, 学习是一种与学生个体的内在相 关联的、更加多元化的和极具赋有意义的活动, 其所赋予个体的符号不再 是学生而是学习者。

\section{1 影响学习者身份建构的因素}

一个自然人从学生向学习者身份的转变不是一蹴而就的, 而是受多重 因素的制约与激励。这也就决定着现代学生学习者身份的构建受来自学生 自身、教师、同窗、学校文化和社会层面的多重影响。

\section{1 学生个人层面}

在学校教育的评价中, 学业水平主要是指学生的学习成绩, 其衡量的 标准主要是由学生的考试分数来决定的。从目前来看, 考试分数不仅仅是 学校评价学生的重要标准, 也是家长和社会衡量一所学校教学质量的一项 重要参照。学生作为学习者的身份形成过程中, 学业水平会对其产生至关 重要的影响。它主要表现在两个方面:一是影响教师对学生的认知和关注, 二是影响学生对自身的认知。学习成绩是对学生学习过程的一种直接评价, 学习成绩优秀的学生一般具有积极向上的自我效能感, 与此呼应的, 学生 对自身的自信心也会不断增强, 并善于肯定自我和鼓励自我。

\section{2 教师期待层面}

教师对学生的关注既是影响学生学业成就的重要影响因素, 也是影响 他们对自身作为学习者身份的认知。对于学生而言, 教师的关注不仅是对 学生自身的一肯定, 是他们存在感的一种表征, 也是学生情感需求的一种 寄托, 尤其是在中小学时期, 绝大多数学生都希望能够得到教师的关注。教 师的关注对于学生的学业成绩及未来发展具有显著的促进和预测作用, 心 理学中的 “皮格马利翁效应” 已经非常明确地体现了教师期待、教师关注 对学生的影响。当教师期待学生成为什么样的人时, 学生就能够感受到一 种被关注和重视的体验, 也会无意中投入更多注意, 从而建立了一种良性 循环。

\section{3 同窗评价层面}

在学生的学习过程中, 作为他者的学生是每个学生认识自我的一面镜 子。从身份的概念来看, 学生不仅要认识自己眼中的 “我”, 也要知道他人 眼中的“我”。换句话来说, 通过他人的评价也是认识自己的一种重要方式。 这一点在基础教育阶段尤为明显, 这是因为在基础教育阶段, 学生多是未 充分发展成熟的个体, 他们往往会比较关注自己在他人眼中的形象, 在意 他人对自己的看法和评价。这种看法和评价直接影响着学生同伴之间的关
系和交往, 而这种同伴关系恰恰是学生获得归属感的一种重要方式。通常, 大多数学生都会以他人的评价作为认识自我的一个参照, 例如 “大家都认 为我很聪明, 认为我是一个优秀的学生”, 而我为了维持这种 “好学生” 的 形象, 就必须做出某种行为或是改变来继续保持这种形象。同时, 学生自身 也会采用与他人比较的方式来认识自我, 如通过比较学习好成绩的高低来 评价自己的学习结果, 了解自身在班级中所处的位置; 通过比较在教师眼 中的形象的来改变或重新定位自我。总而言之, 在学生的整个学习历程中, 作为他者的学生总是在某种程度上以特定的方式对学生身份的形成产生 着重要影响。

1. 4 学校文化层面

学校是学生身份赖以存在的前提之一, 学校文化对于学生作为学习者 的身份建构也具有重要的影响。长期以来, 学校一直是一个比较封闭的组 织机构, 尽管学校也一直在进行着改革, 但是这种变化主要体现在外在的 基础设施、物质条件等物理环境方面的改善, 而内在的改变并不是十分突 出。物质因素的改变使得教师和学生之间的互动变得更为便捷, 信息传递 的途径更加的有效, 这种改变对于优化教师教学和学生学习的过程深有帮 助。然而, 这种改变依旧停留在表层, 一些内在的、属于文化结构层面的改 变效果甚微。学生作为学习者身份的建构需要有良好的学校文化氛围作为 支撑, 一方面, 学校对学生的评价应该不再是以考试和分数为导向, 而是应 该关注学生在学习过程中自主性的发挥程度; 另一方面, 需要促进学生在 学校、在班级中归属感的获得, 这就需要学校营造一种以人为本的校园文 化环境, 进而增强学生的情感投入。

1.5 社会影响层面

在促使学生向学习者转变, 建构学生作为学习者身份的过程, 社会层 面的因素也对其产生了极其重要的影响。首先, 当前的社会已经步入了终 身学习的阶段, 这也就意味着终身学习不再只是一种发展理念和愿景, 而 是一种要立足于社会所必须具备的一种学习能力。其次, 学习者的学习是 一种个性化学习, 它是对学校教育的一种延伸、解放和补充。如果学校的 学习方式处于一种较为封闭的状态, 个性化学习恰恰可以中和这种固有的 局限, 但这种个性化学习需要一定的物质基础作为支撑。比如, 能够随时随 地访问的资料库, 能够灵活携带的移动设备设施, 能够公开获取的课程资 源等。通过这些丰富的学习资源, 可以开拓学生的眼界, 提高学生的思辨能 力与创造能力。如果外在的社会环境难以提供支撑个性化学习的平台和环 境, 那么学生的学习渠道将受到很大的限制。因此, 学生个性化学习的实现 离不开社会的支持与帮助。

\section{2 学习者身份的构建策略}

作为对学生学习能力的一种评价维度, 构建学生的学习者身份需要整 
合多种教育资源, 从而使教育主体、学校教育和学生自身形成一股强有力 的合力, 各美其美, 美美与共。

\section{1转变教育主体的角色认知}

从自我和他者的关系视角而言, 身份不仅意味着个体自身对“我是谁” 的感知, 也意涵着在他人眼中 “我是谁” 的图像。因此, 对个体身份的确定 既要从个体自身的角度出发, 也要结合外界 (重要) 他人对 “我” 的看法。 在学生作为学习者身份的建构过程中, 教师认知的转变和学生自身认知的 转变是最为关键的前提条件, 在此二者转变的基础上, 学生作为学习者身 份的建构才成为可能。

\section{2 坚持以学习者为中心的教学}

对学生而言, 教师是最为关键的 “重要他人”, 教师不仅影响着学生对 学习内容的掌握, 也影响学生对自我的认知。在传统的课堂上, 教师控制着 学生的学习过程, 从而导致学生的学习动机、自信心和对学习的热情不可 避免地会受到一定的负面影响, 学生失去了对学习的责任和热情。这一问 题引起了不少研究者的反思 “学习者为什么会这样?为什么有这么多的学 生感到忧虑不安、做事优柔寡断而且对自己学习者的身份不确定? 是不是 我们有些教学方法阻碍了学生作为学习者的发展?”不言而喻, 学校应该是 作为学生发挥其才能的地方, 而培养学生终身学习的技能以及使用这些技 能的信心, 重塑学生对自身作为学习者的认识和理解是教师非常重要的任 务之一。对于教师而言, 要达成上述愿景, 就要坚持以学习者为中心的教学, 以学习者为中心的教学不仅仅是一种促进学生向学习者转变的途径, 也是 一种提高教师教学水平和质量的有效手段。

2. 3 实现个性化学习的支持与配合

随着科学技术的飞速发展, 这为实现学生的个性化学习提供了多种可 能。而学习是实现学生身份转化的优选路径。美国教育部将个性化学习定 义为: “个性化学习是一种学生体验, 学习的速度和教学方法是针对每个学 生的需要进行优化的, 符合标准的学习目标、教学方法和教学内容 (以及它 的排序) 可能根据学习者的需要和兴趣而有所不同。学习活动是有意义的, 并与学习者相关, 是由他们的兴趣和过去的表现驱动的, 通常是自我启动 或自我选择的。” 学习者身份是学生在大量的有效的学习实践中构建起来 的, 内驱外动, 相互统一, 满足学生个性发展的过程, 也是在实现学生身份 转换的过程。

2. 4 重视学以致用与创造能力的培养
学习者身份的构建是为适应高速发展的未来社会做准备的, 而我们学 到的知识不能是头脑里的摆设品, 我们需要把知识作为一种 “能源” 去传 播、运用和实践, 以期实现知识本身的价值。与此同时, “学习者” 不应 仅仅停留在就地学习这一个层面上, 当这部分人的知识水平和学习能力 达到一定水准时, 就应该发挥自身的创造力, 其实, 这时学习者身份也相 应地步入了一个崭新的阶段——自我探索与创新。创新思维与批判思维 的形成才是真正达成学校教育的育人目标, 与此同时, 这也是学习者学 习的终极目标。

\section{3 结语}

随着终身学习和学习型社会的不断深入, 学习者身份必将是未来社 会的一种新的身份图像。“学习者” 身份不仅可以满足社会发展的需求, 还可以为个体的不断发展注入新兴活力。从某种程度上来说, 这对学校 教育的育人目标提出课更高的要求, 学校教育应该创新教育范式, 主动 促使个体从学生向学习者身份的转变, 从而达成 “人人都是学习者” 的 终身学习愿景。

\section{[参考文献]}

[1] 李茂森. 教师身份认同研究 [M]. 北京: 北京师范大学出版 社,2014:56-58.

[2]叶菊䎦.教师身份构建的历史社会学考察 [M].北京: 北京师范大学 出版社,2017:72-75.

[3] 叶澜. “生命. 实践” 教育学论纲 $[M]$. 上海: 华东师范大学出版 社,2015:110-113.

[4]程介明.学校管理与学生身份[J].上海教育,2013(10):46.

[5]程毅. “将身份放入话语中”: 从话语维度谈当前身份研究的现状及 趋势[J].文艺评论,2016(03):43-48.

[6]崔彦,代中现. 以学习者为中心的教学设计与实践 [J]. 全球教育展 望,2010(06):36-39+49.

[7]余宏亮.教师作为知识分子的角色重构研究 [D]. 西南大学,2014(9):201.

[8]赵健.学习共同体一关于学习的社会文化分析 [D]. 华东师范大 学, 2005:22-24.

作者简介：

杨晓旭(1992--), 女, 汉族,山东淄博人, 硕士研究生, 研究方向: 课程 与教学论。 